\title{
Glacier hydrological process modeling based on improved SWAT+: A case study in the Upper Yarkant River Basin
}

\author{
Chengde Yang ${ }^{1}$, Min Xu ${ }^{1}$, Congsheng $\mathrm{Fu}^{2}$, Shichang Kang ${ }^{1}$, and Yi Luo ${ }^{3}$ \\ ${ }^{1}$ Northwest Institute of Eco-Environment and Resources \\ ${ }^{2}$ Nanjing Institute of Geography and Limnology Chinese Academy of Sciences \\ ${ }^{3}$ Institute of Geographic Sciences and Natural Resources Research Chinese Academy of \\ Sciences
}

February 17, 2022

\begin{abstract}
Glaciers have proven to be a particularly sensitive indicator of climate change, and the impact of glacier melting on downstream water supplies is becoming increasingly important as the world's population expands and global warming continues. Data scarcity in mountainous catchments, on the other hand, has been a substantial impediment to hydrological process simulation. Therefore, an integrated glacier hydrological process module was introduced for the Soil and Water Assessment Tool Plus model (SWAT+), in which an enhanced temperature-index glacier melt algorithm considering solar radiation was employed to maintain model clarity and favorable performance in this study. Furthermore, SWATplusR was introduced for sensitivity analysis using the Sobol approach, and Integrated Parameter Estimation and Uncertainty Analysis Tool Plus (IPEAT+) was coupled with this enhanced model (SWAT+Glacier) to perform calibration and validation in the Upper Yarkant River (UYR) basin. The result indicated that (i) including glacial-hydrological processes considerably improved simulation precision, with an NSE promotion of 2.6 times and $\mathrm{R}^{2}$ of 1.7 times greater than the original model; (ii) it is an efficient and feasible way to simulate glacial-hydrological processes with SWAT+Glacier and calibrate it using observed discharge data in data-scarce and glacier melt dominated catchments; and (iii) we discovered that glacier runoff is intensively distributed throughout the summer season, accounts for about $78.5 \%$ of the annual glacier runoff, and glacier meltwater provides approximately $52.5 \%\left(4.4 \times 10{ }^{9} \mathrm{~m}\right.$ ${ }^{3}$ ) of total runoff in the study area.
\end{abstract}

\section{Hosted file}

submit_Glacier process modeling using SWAT+ A case study in the Upper Yarkant River Basin.docx available at https://authorea.com/users/461079/articles/556854-glacier-hydrological-processmodeling-based-on-improved-swat-a-case-study-in-the-upper-yarkant-river-basin 